\title{
Application of Polyurethane Polymer and Assistant Rails to Settling the Abnormal Vehicle-Track Dynamic Effects in Transition Zone between Ballastless and Ballasted Track
}

\author{
Caiyou Zhao, ${ }^{1,2}$ Ping Wang, ${ }^{1,2}$ Qiang Yi, ${ }^{1,2}$ and Duo Meng ${ }^{1,2}$ \\ ${ }^{1}$ Key Laboratory of High-Speed Railway Engineering, Ministry of Education, Southwest Jiaotong University, Chengdu 610031, China \\ ${ }^{2}$ School of Civil Engineering, Southwest Jiaotong University, Chengdu 610031, China
}

Correspondence should be addressed to Ping Wang; 381657901@qq.com

Received 16 November 2014; Revised 24 March 2015; Accepted 25 March 2015

Academic Editor: Toshiaki Natsuki

Copyright (C) 2015 Caiyou Zhao et al. This is an open access article distributed under the Creative Commons Attribution License, which permits unrestricted use, distribution, and reproduction in any medium, provided the original work is properly cited.

\begin{abstract}
This paper describes tests on a transition section between ballasted and ballastless tracks in the Liupanshui-Zhanyi railway in China. The originally unsettled transition zone is exposed to sudden car shaking and a series of track transition problems during train passage. As an example, the influences of polyurethane polymer and a combination of polyurethane and assistant rails to increase track stiffness distribution and track transition decay rates on the dynamic vehicle and track behaviour were investigated. The measured results indicate using only polyurethane and using both polyurethane and assistant rails not only effectively makes the track stiffness change more even but also increases the track decay rate at the target frequencies. These positive effects further reduce the wheel-rail interaction forces and vehicle and rail vertical acceleration, which decreases more when combining polyurethane and assistant rails than when using only polyurethane because the former outperforms the latter for smoothing the track stiffness distribution and increasing the track decay rate. Based on abating wheel-rail impact during the transition from ballasted to ballastless track and improving traffic operation and passenger comfort, combining polyurethane and assistant rails had the greatest effect and may be an effective remedy.
\end{abstract}

\section{Introduction}

The transition between ballasted and ballastless track is a weak point in heavy haul and high-speed railways (Figure 1). Strong vibrations occur in the train, railway track components, and support structures when the trains transition between ballasted and concrete slab tracks. These vibrations may cause mud pumping of the ballast, swinging, or hanging sleepers, ballast breakdown, rail battering, concrete sleeper cracking and differential settlement, and loss of surface and gauge. These problems then directly affect the running stability of the trains and may even create the potential for derailment.

These problems associated with the transition section are well recognized and have been extensively investigated and researched worldwide. Some studies focused on modelling and simulating the vehicle-track interaction in these sections, and the principle vibration source is thought to be the abrupt change in track stiffness during the transition due to the concrete slab track stiffness being far larger than that of the ballast track [1-10]. Other studies investigated remedies to effectively address the resultant problems. In general, most approaches that have been tested and proven effective at vibration control in the railway transition section, such as using larger sleepers, resilient sleepers, and track-lifting techniques [11-13], have reduced the abrupt change in track stiffness. However, such measures may be expensive and difficult to apply to an established railway.

An alternative approach is discussed here. Polyurethane and assistant rails are used to reduce the abrupt track stiffness change between ballasted and ballastless track to control strong vibrations. The even change in the track stiffness using polyurethane and assistant rails can therefore be expected to 


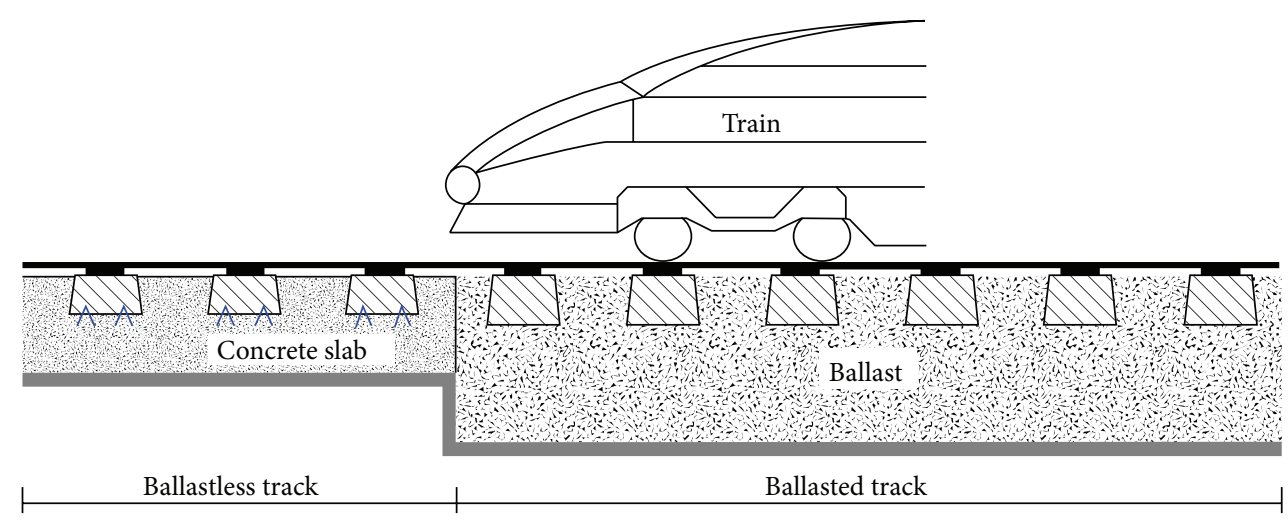

FIgURE 1: A schematic layout of the railway ballastless-ballasted transition.

reduce rolling stock and track and foundation component degradation at these transitions.

This paper describes the circumstances and test results for a particular tunnel-bridge transition section where polyurethane and assistant rails were introduced. The ballastless track and ballasted track lay in the tunnel and bridge sections, respectively. Before applying the above mentioned remedy, broken cut spikes, broken tie plates, cracked concrete ties, and even broken rails have occurred at this location in addition to severe vibration in the car when the train passes this section. Under these circumstances, the Key Laboratory of High-Speed Railway Engineering, commissioned by Chengdu Railway Bureau, conducted extensive studies and field tests to investigate the root cause to these problems and proposed a remedy using polyurethane and assistant rails to settle the abrupt track stiffness change.

The research presented here focuses on exploratory evaluations on controlling the abrupt change in the track stiffness during the transition between ballasted and ballastless track using polyurethane and assistant rails via in-situ testing. First, the vertical static track stiffness in the transition section before and after settlement was studied to determine the abrupt track stiffness change effect. The train-induced vertical acceleration of both the rail and vehicle in the transition zone and the vertical wheel-rail force when the train passes through the transition zone before and after settling was tested to characterize the vibration control effect. Finally, the vertical vibration attenuation rates were measured before and after settlement and supplemented by further analysis after applying polyurethane and assistant rails to define their effect on the wheel and track vibration characteristics in the transition section.

\section{Field Testing}

2.1. The Site. The field investigations were performed on the $212.2 \mathrm{~km}$ long Liupanshui-Zhanyi railway, an important part of the Shanghai-Kunming railway, which starts from Liupanshui railway station in Guizhou province and ends at the Zhanyi railway station in Qujing, Yunnan province. This railway is a national, first-level, automatic block section of double-tracked electric railway designed for speeds of
$160 \mathrm{~km} / \mathrm{h}$. The line carries 70,000,000 t of freight per year and 34 pairs of passenger trains per day.

A $25 \mathrm{~m}$ long section of the Liupanshui-Zhanyi Railway line consisting of the Guanyin River Bridge, a transition, and the Sanlian Tunnel zones were selected to analyse the accessibility because much of the railway passes through mountainous regions. The bridge is a $248 \mathrm{~m}$ long double track T-girder concrete bridge. The track structure on the bridge is a ballasted one. The line is a continuously welded $60 \mathrm{~kg} / \mathrm{m}$ rail with concrete sleepers with $0.6 \mathrm{~m}$ spacing, approximately $0.339 \mathrm{~m}$ deep ballast layer, and WJ-7 fastening system. The tunnel is a $12214 \mathrm{~m}$ long double-track tunnel with a $125 \mathrm{~m}^{2}$ cross-sectional area. The track structure for the line in the tunnel is ballastless. The line is also a continuously welded $60 \mathrm{~kg} / \mathrm{m}$ rail with a $0.625 \mathrm{~m}$ sleeper spacing, approximately $0.315 \mathrm{~m}$ thick track bed slab, and WJ-7 fastening system. The $25 \mathrm{~m}$ long transition section comprises 5 metres of ballastless track and 20 metres of ballasted track. The settlement was implemented over two steps. The first step involved spraying polyurethane onto the ballasted track bed in three ways. The second step laid $25 \mathrm{~m}$ long $60 \mathrm{~kg} / \mathrm{m}$ assistant rails in the transition section.

2.2. Remedy of Transition Section. The general idea for this remedy is that a 25 metre transition section was setup between the tunnel and bridge sections. The transition section consisted of 5 metres of ballastless track and 20 metres of ballasted track. Two assistant rails were laid for each railroad track throughout the entire transition section. The ballasted track in the transition section was settled in three segments. The first segment, immediately adjacent to the ballastless track, coated all ballasts with polyurethane. The second segment, immediately adjacent to the first section, coated the ballasts beneath the sleepers and shoulder ballasts with polyurethane. The last segment coated only the ballasts beneath the sleepers with polyurethane. See Figure 2 .

The transition section settlement process is shown in Figure 3 and was performed in the following stages: (a) drying and cleaning the track bed transition section, (b) spraying polyurethane onto the ballasted track bed, (c) maintaining the transition zone track bed after spraying with polyurethane, and (d) laying assistant rails throughout the 




FIgURE 2: A schematic layout of the transition zone.
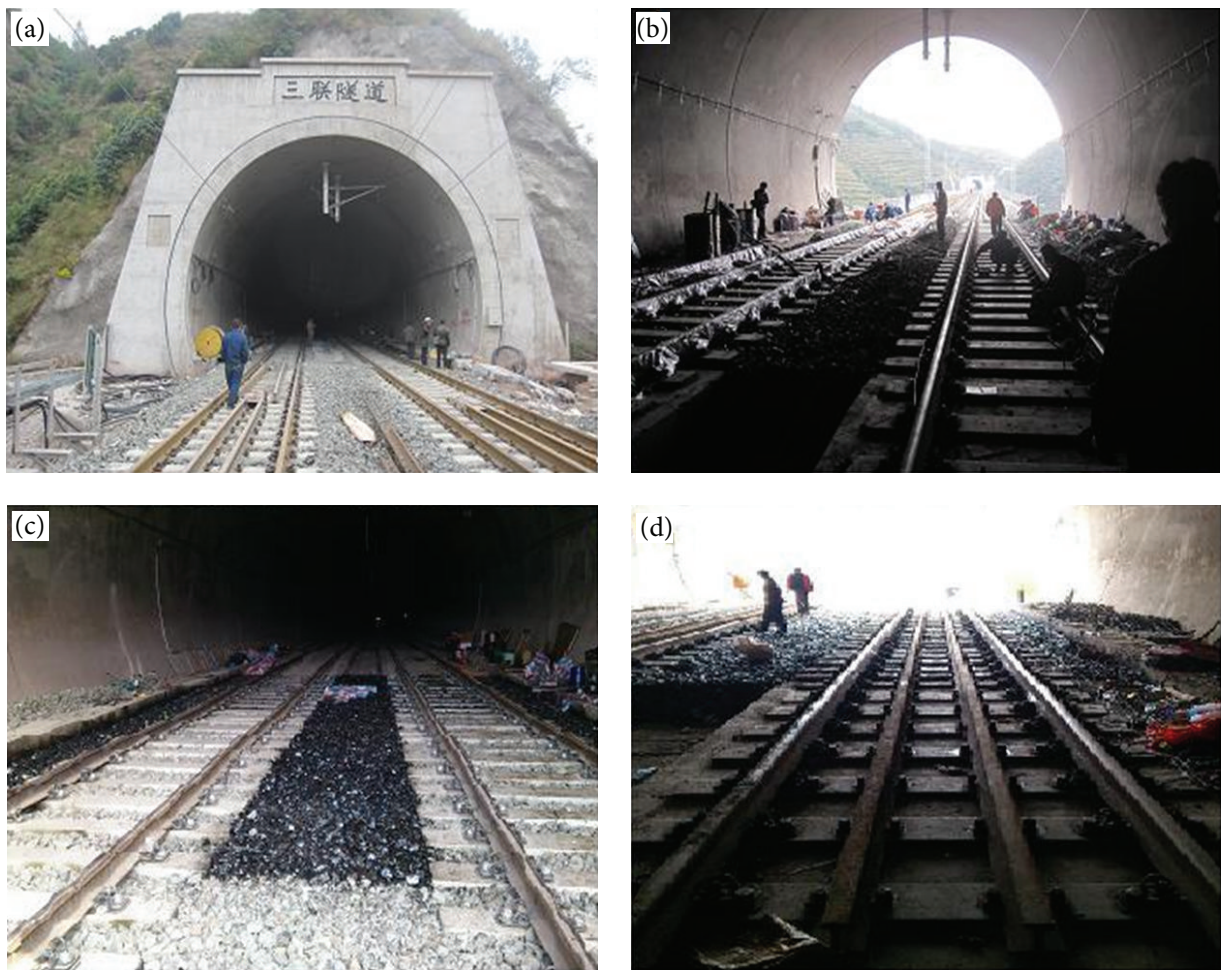

FIGURE 3: Photos of the transition zone: global graph of the transition zone before settlement (a), graph of the process of spraying polyurethane polymer (b), graph of the transition zone after spraying polyurethane polymer (c), and graph of the transition zone after laying assistant rails (d).

transition zone. The physical and mechanical properties of the polyurethane used in this research are shown in Table 1.

2.3. Experimental Set-Up. This study was divided into three stages that focused on comparing the abrupt vertical static track stiffness, the effect of settlement on the vibration in the transition section tracks, and comprehensively analyzing the wheel-rail force and corresponding vibration in the vehicle and rail when a train passes through the transition section.

Vertical static track stiffness tests evaluated the settlement control mentioned in this research. Twenty-six dial indicators were placed at 13 locations (two indicators on the left and right rail foot at each location) longitudinally along the track as shown in Figure 4. A portable jack was used to apply a vertical load directly to the railhead surface as shown in Figure 5(a). Five tests were repeated at each location. The average static track stiffness from five repeat tests at each location was then calculated for further analysis.

The track decay rates, which quantify the rail vibration attenuation distance along the track, were used to investigate the effect the settling developed in this research had on the transition section vibration performance. The accelerometer 


\begin{tabular}{cccccc} 
& \multicolumn{2}{c}{ Transition section } & \\
\hline Ballastless track & $*$ & & Ballasted track & \\
\hline 5 & $*$ & $7 \mathrm{~m}$ & $*$ & $7 \mathrm{~m}$ & $* 6 \mathrm{~m}$ \\
$*$
\end{tabular}

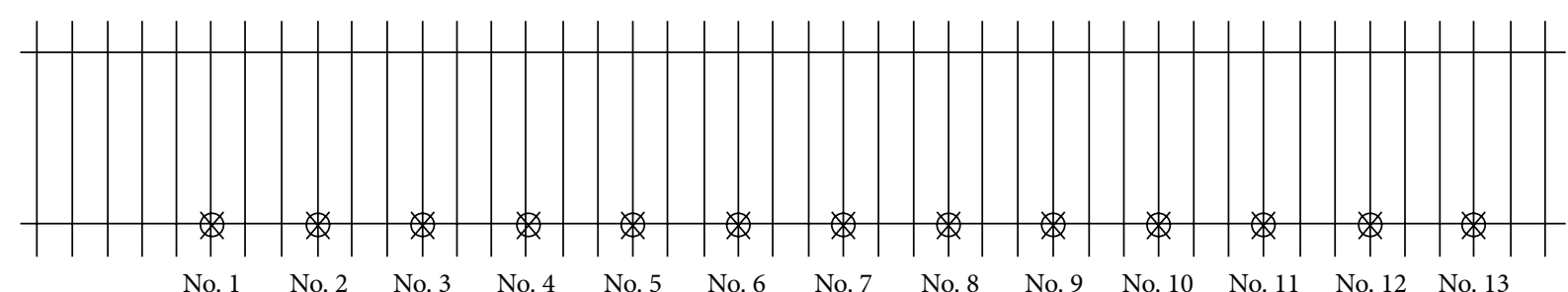

FIGURE 4: Layout of the locations of the dial indicators (accelerometers).
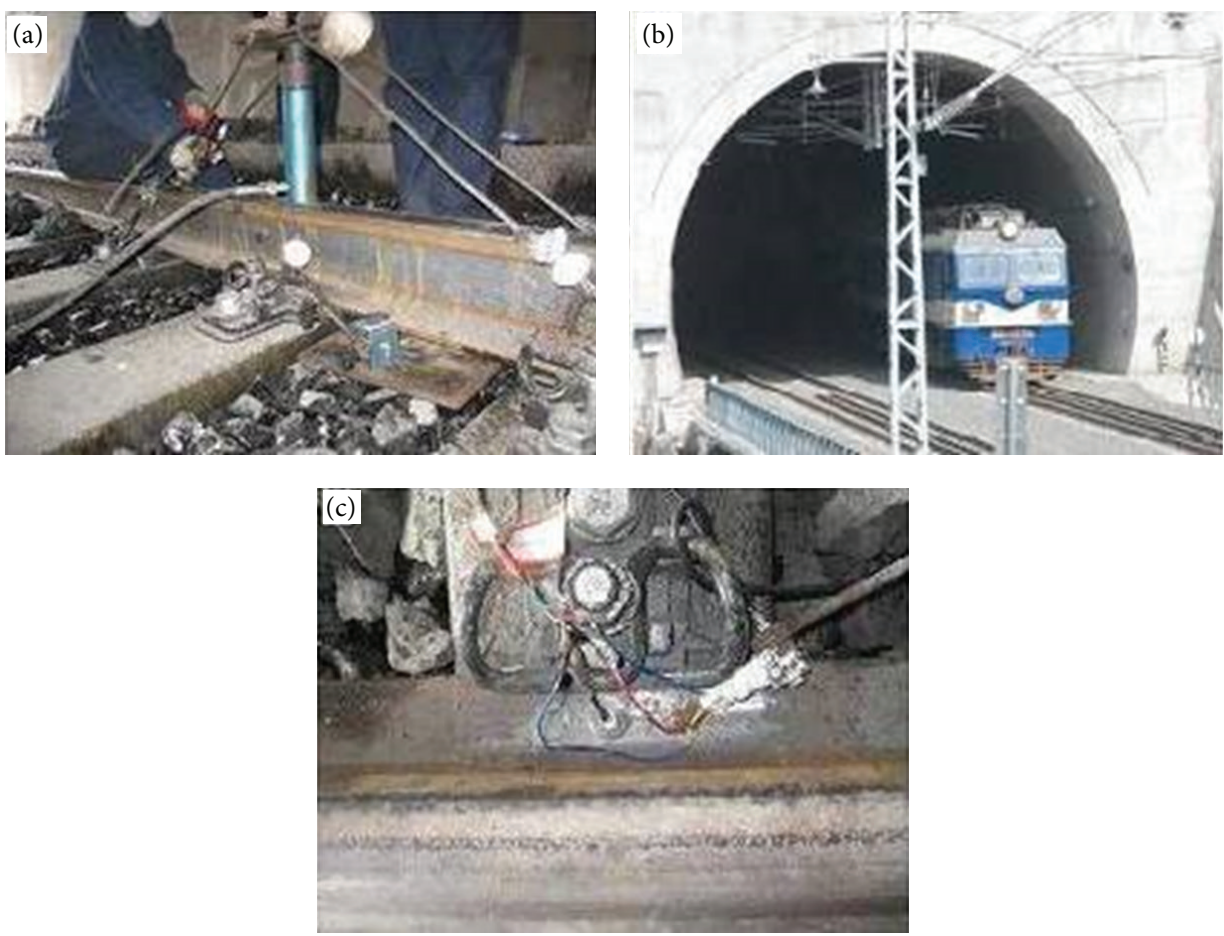

FIGURE 5: In-situ tests: vertical static track stiffness test (a), the train passing through the transition section (b), and layout of accelerometers on rails (c).

TABLE 1: Physical and mechanical properties of the polyurethane polymer.

\begin{tabular}{lc}
\hline Properties & Value \\
\hline Density $\left(\mathrm{g} / \mathrm{cm}^{3}\right)$-ISO 1183 & 1.20 \\
Shore hardness $\left({ }^{\circ}\right)$-ISO 868 & 100 \\
Bond strength (MPa)-ISO-10364-1993 & 5 \\
Tensile strength (MPa)-ISO 37-2005 & 20 \\
Breaking elongation (\%)-ISO 37-2005 & 300 \\
Low-temperature brittleness $\left({ }^{\circ} \mathrm{C}\right)-$ ISO 812-1991 & -70 \\
Compression strength (MPa)-ISO 604-2002 & 40 \\
\hline
\end{tabular}

layout, test implementation, and measurement directions from sensor 1 to 13 followed references $[14,15]$.
To detect the effect the settling recommended in this paper had on controlling inordinate vibrations in the train and railway track components, the comparative and comprehensive dynamic responses for the vehicle-track system were measured as trains passed through the transition section. The vertical wheel-rail contact forces were measured using an instrumented wheelset installed on the vehicle. The vertical acceleration of the vehicle and rails were measured using 2 accelerometers on the vehicle and 26 accelerometers on the rail foots (as shown in Figure 5(c)). The measurement point layout on the rails is the same as for the above static vertical static track stiffness test. A data acquisition system consisting of a DHDAS-5920 PULSE modulator and twenty-eight LC acceleration detectors were installed to record the vibration parameters and measured accelerations, respectively. The accelerometers were fastened to the measured construction 
using an epoxy resin. A sampling frequency of $25,600 \mathrm{~Hz}$ was used and data for each passing train was recorded for approximate $90 \mathrm{~s}$. The sensors used to measure the rail acceleration could record frequencies between 0.2 and $11,000 \mathrm{~Hz}$; those used to measure the vehicle acceleration could record frequencies between 0.1 and $2000 \mathrm{~Hz}$. The Shaoshan-3 train (as shown in Figure 5(b)) travelling at $140 \mathrm{~km} / \mathrm{h}$ was used for these tests.

\section{Testing Results and Discussion}

3.1. Static Track Stiffness Test Results. To study how a single in-situ polyurethane application and combining the in situ polyurethane and assistant rails improved the railway track safety and performance, the vertical static track stiffness in the transition zone was measured without any settlement, with only polyurethane, and with a combination of polyurethane and assistant rails as shown in Figure 6.

A sudden change in the track stiffness was found between the ballasted and ballastless track sections before settlement. The vertical track stiffness for No. 1 in the ballastless track zone was $203 \mathrm{kN} / \mathrm{mm}$; however, the vertical track stiffness for No. 2 immediately adjacent to No. 1 in the ballasted track zone was $109 \mathrm{kN} / \mathrm{mm}$. The former is twice the latter. The vertical track stiffness at the rest measuring points decreased gradually and slowly from No. 3 to No. 13 .

The vertical track stiffness at each measuring point was larger after applying polyurethane than without the settlement; moreover, the change in the vertical track stiffness was more even. The vertical track stiffness at No. 2 increased from $109 \mathrm{kN} / \mathrm{mm}$ to $165 \mathrm{kN} / \mathrm{mm}$ after applying polyurethane. Meanwhile, the vertical track stiffness at the rest measuring points also decreased gradually and slowly. Furthermore, adding assistant rails, that is, combining polyurethane and assistant rails, more evenly spread the sudden vertical track stiffness than applying only polyurethane.

3.2. Track Decay Rates Test Results. The parameter with the strongest influence on the medium-high frequency rail vibration and amount of noise radiated from the rail was the vibration decay rate in the vertical direction along the rail, usually expressed in $\mathrm{dB} / \mathrm{m}$ [15]. For the transition section studied in this research, the calculated and measured decay rates are shown in Figure 7 based on the method described in references $[14,15]$. In general, the track decay rates at frequencies above $100 \mathrm{~Hz}$ generally increased after applying the polyurethane and assistant rails compared to before the settlement. On one hand, the corresponding track decay rate shown by the red curve in Figure 7 was noticeably enhanced at frequencies above $100 \mathrm{~Hz}$, especially for frequencies ranging from 125 to $1250 \mathrm{~Hz}$, compared to that without settlement shown by the green curve, as a result of the use of the polyurethane polymer. This rise in decay rate in the measurement towards $100 \mathrm{~Hz}$ is due to the fact that the coupling and interaction between the rail and the subrail foundation was enhanced. On the other hand, comparing the decay rate after combining polyurethane and assistant rails to that for using polyurethane indicates the

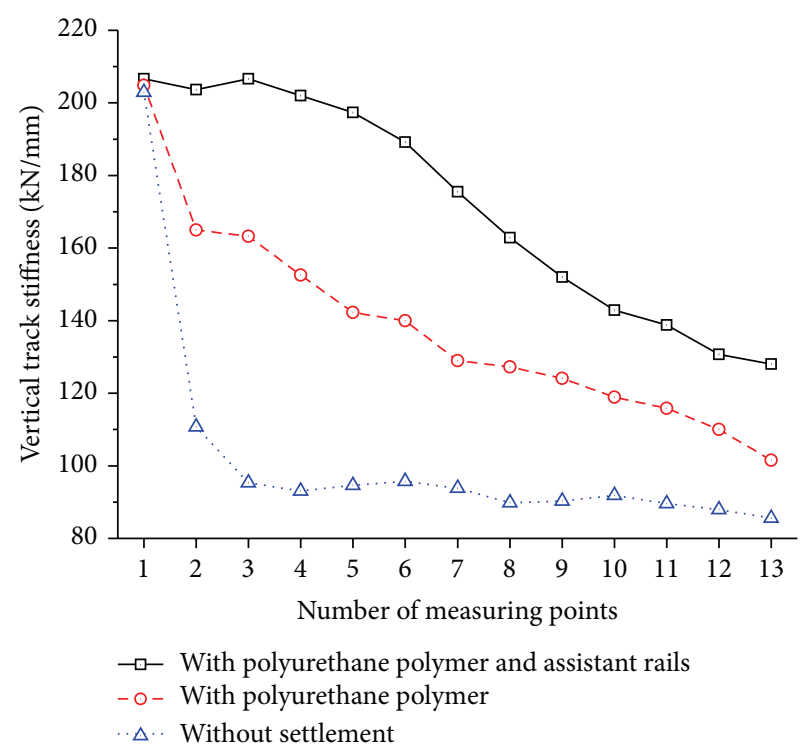

FIgURE 6: Vertical track stiffness of the transition section.

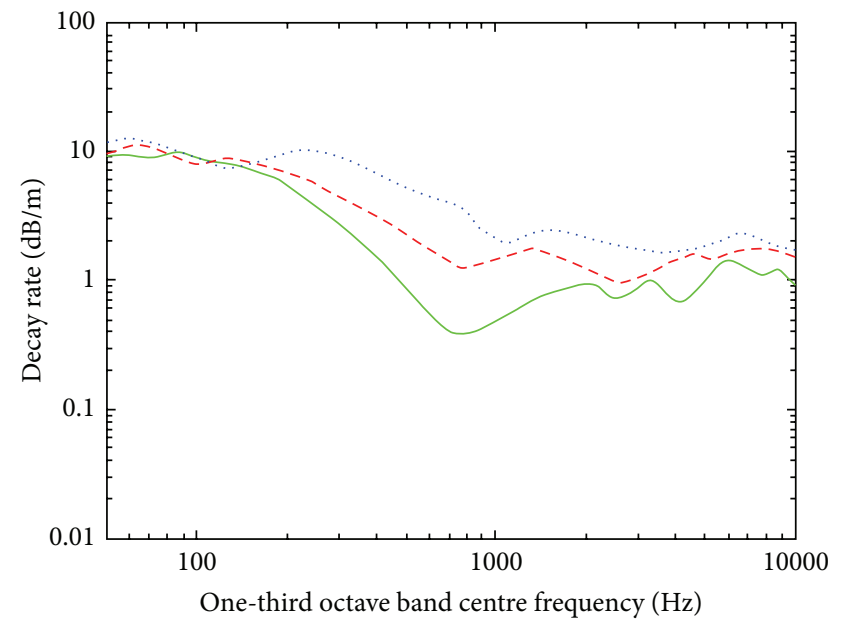

FIGURE 7: Measured track decay rates: without settlement (green line), with polyurethane polymer alone (red line), and with the combination use of polyurethane polymer and assistant rails (blue line).

decay rate was further improved in the frequency range from 100 to $10000 \mathrm{~Hz}$ because the coupling and interactions were enhanced further. These increased decay rates help reduce the medium-high frequency vibration of the rail and noise radiated by the rail.

3.3. Dynamic Responses of the Vehicle-Track System Test Results. To study the effect that applying only polyurethane and combining polyurethane with assistant rails had on the vehicle-track coupling system dynamic responses, the output results, including rail and vertical accelerations and the vertical interaction forces between the wheel and rail, were studied for the three transition patterns. Additionally, 


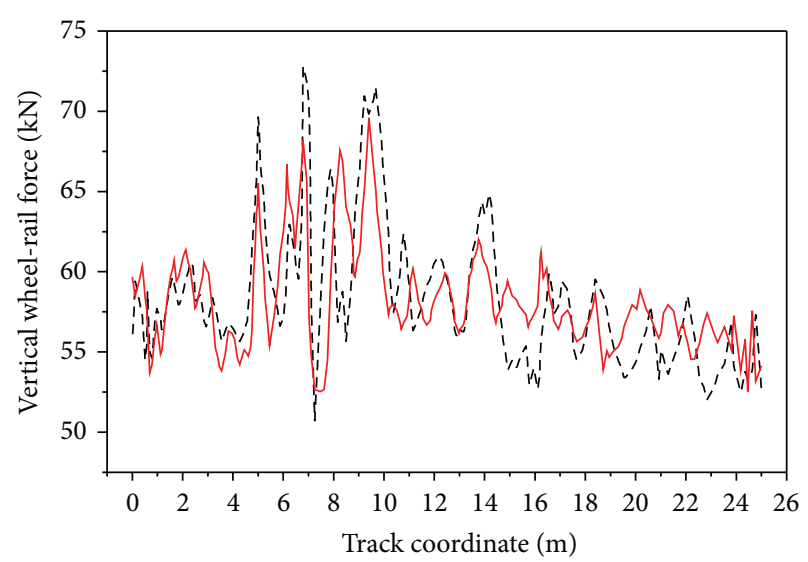

(a) Without settlement

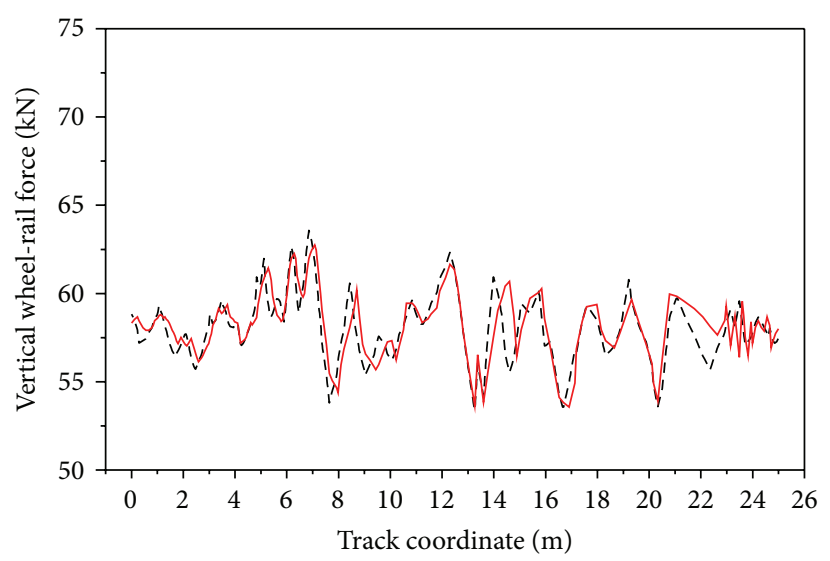

(b) With polyurethane polymer alone

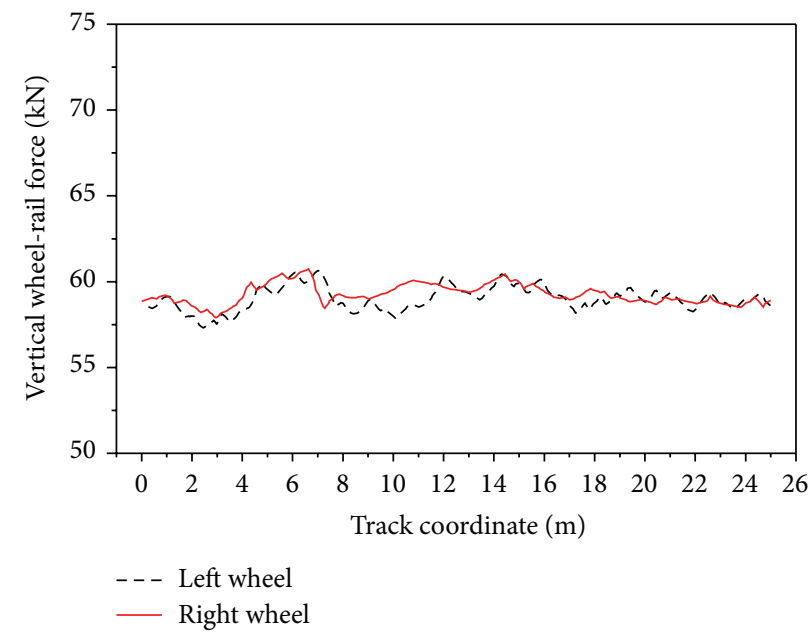

(c) With polyurethane polymer and assistant rails

FIGURE 8: Influence of track stiffness distribution on wheel-rail contact force.

TABLE 2: Maximum wheel-rail contact forces and reduction ratios for different settlement patterns.

\begin{tabular}{|c|c|c|c|c|c|c|}
\hline \multirow{2}{*}{$\begin{array}{l}\text { Transition settlement pattern } \\
\text { Type of wheel }\end{array}$} & \multicolumn{2}{|c|}{ Without settlement } & \multicolumn{2}{|c|}{$\begin{array}{l}\text { With polyurethane polymer } \\
\text { alone }\end{array}$} & \multicolumn{2}{|c|}{$\begin{array}{c}\text { With the combination use of } \\
\text { polyurethane polymer and } \\
\text { assistant rails }\end{array}$} \\
\hline & Left wheel & Right wheel & Left wheel & Right wheel & Left wheel & Right wheel \\
\hline $\begin{array}{l}\text { Upper peak of wheel-rail contact } \\
\text { force }\end{array}$ & 72.79 & 69.60 & 63.60 & 62.74 & 60.69 & 60.74 \\
\hline $\begin{array}{l}\text { Lower peak of wheel-rail contact } \\
\text { force }\end{array}$ & 50.71 & 52.53 & 53.32 & 53.56 & 57.30 & 57.90 \\
\hline $\begin{array}{l}\text { Variance between upper and } \\
\text { lower peak of wheel-rail } \\
\text { contact force }\end{array}$ & 22.08 & 17.07 & 10.28 & 9.18 & 3.39 & 2.84 \\
\hline $\begin{array}{l}\text { Reduction ratio compared with } \\
\text { without settlement (\%) }\end{array}$ & 0 & 0 & 53.4 & 46.2 & 84.6 & 83.3 \\
\hline
\end{tabular}

the trains were driven from the tunnel section to the bridge section.

3.3.1. Vertical Wheel-Rail Contact Force Distribution. Figures $8(\mathrm{a}), 8(\mathrm{~b})$, and 8 (c) show the curves for the wheel-rail contact force distribution when a train travels along a track transition for the three transition conditions. Table 2 is the maximum wheel-rail contact forces and the track stiffness reduction ratios for the different transition patterns. The track stiffness transition pattern exhibited a significant influence on the 


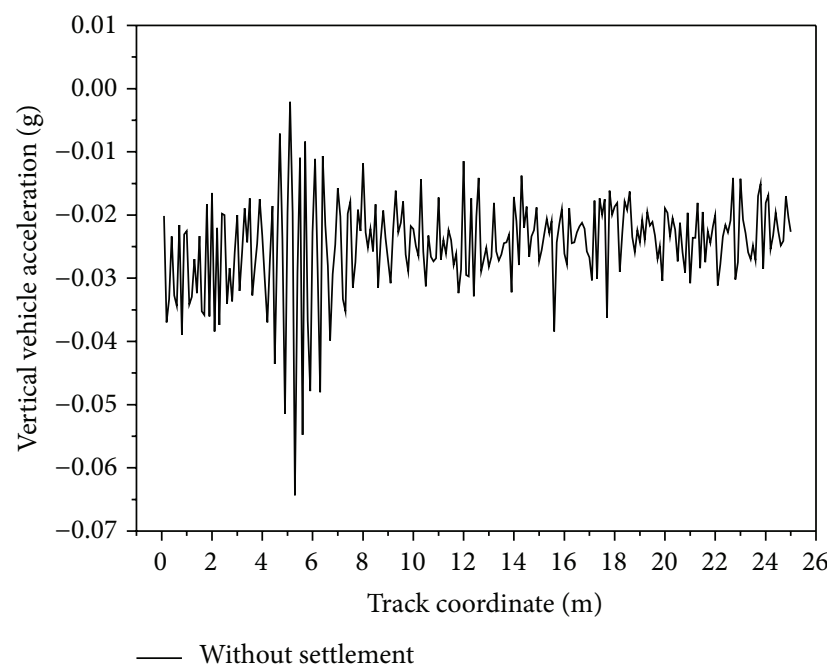

(a) Vertical vehicle acceleration without settlement

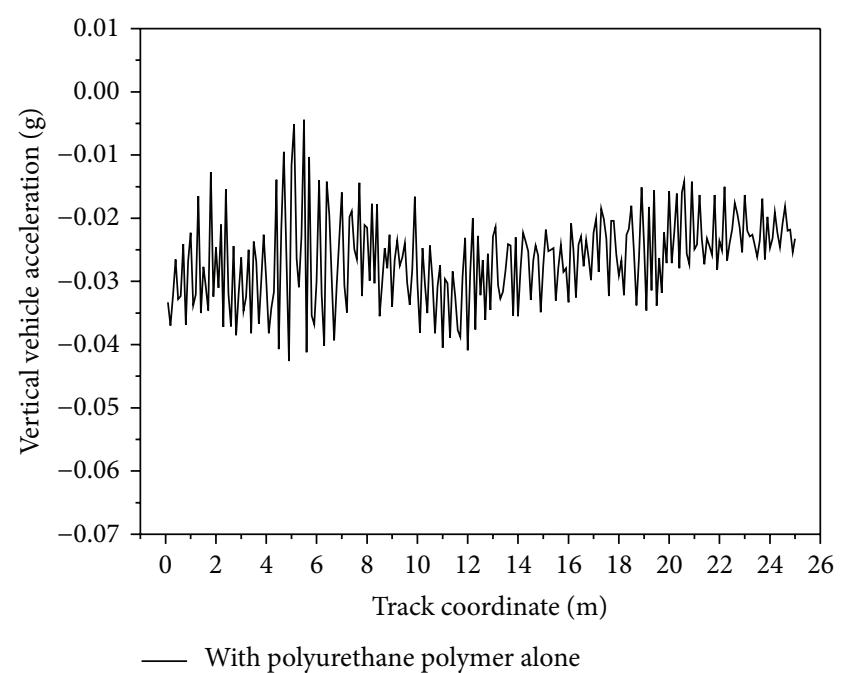

(b) Vertical vehicle acceleration with polyurethane polymer alone

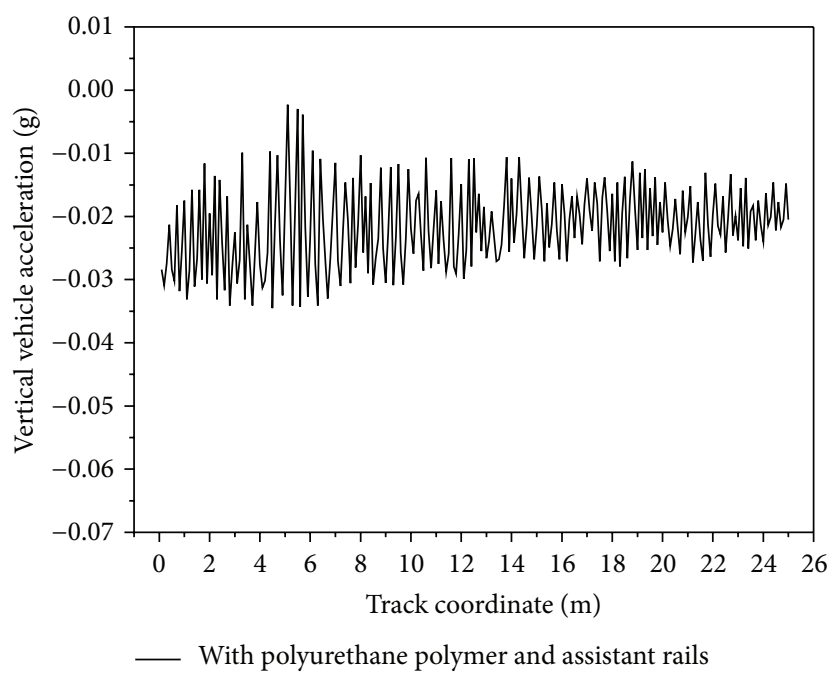

(c) Vertical vehicle acceleration with the combination use of polyurethane polymer and assistant rails

FIgURE 9: The acceleration of a wagon traveling from the bridge to the embankment.

vehicle and track dynamic behaviors and smoothing the track stiffness transitions significantly reduced the wheel-rail interaction forces.

In addition, there were two significant heaves at approximately $12 \mathrm{~m}$ and $19 \mathrm{~m}$ as shown in Figure 8(b). These heaves occurred because of the three-segment application of the polyurethane, and two new, considerably less abrupt stiffness change points occur at the borders.

Based on abating impact and improving traffic operation, combining polyurethane and assistant rails is the best. The maximum wheel-rail contact force reduction occurred for the transition using polyurethane alone and was $53.4 \%$ and $84.6 \%$ for the left wheel and $46.2 \%$ and $83.3 \%$ for right wheel compared to the abrupt track stiffness change (without settlement) when combining polyurethane and assistant rails as shown in Table 2.
3.3.2. Vertical Acceleration Distribution of the Vehicle. The vertical accelerations in the vehicle for a train travelling through the three types of track transition patterns, a vital indicator of passenger comfort, are given in Figure 9. Furthermore, the maximum vehicle accelerations and their reduction ratios for the different transition patterns are shown in Table 3. The maximum vehicle acceleration reached $0.064 \mathrm{~g}$ when there was no settlement in the transition zone, which explains why passengers feel the train passing through a stiffness transition.

The maximum vehicle acceleration decreased to $0.043 \mathrm{~g}$ after applying polyurethane with a maximum reduction of $32.8 \%$ relative to the abrupt track stiffness change (without settlement), as shown in Table 3. However, two other significant peaks occur at $12 \mathrm{~m}$ and $19 \mathrm{~m}$, as shown in Figure 9(b). These peaks result from the three application segments for 
TABLE 3: Maximum rail accelerations and reduction ratios for different transition patterns.

\begin{tabular}{|c|c|c|c|}
\hline Transition pattern & Without settlement & With polyurethane polymer alone & $\begin{array}{c}\text { With the combination use of } \\
\text { polyurethane polymer and assistant } \\
\text { rails }\end{array}$ \\
\hline Maximum rail accelerations & -0.064 & -0.043 & -0.035 \\
\hline $\begin{array}{l}\text { Reduction ratio compared with without } \\
\text { settlement (\%) }\end{array}$ & 0 & 32.8 & 45.3 \\
\hline
\end{tabular}

TABLE 4: Maximum rail accelerations and reduction ratios for different transition patterns.

\begin{tabular}{lccc}
\hline Transition pattern & $\begin{array}{c}\text { Without } \\
\text { settlement }\end{array}$ & $\begin{array}{c}\text { With polyurethane polymer } \\
\text { alone }\end{array}$ & $\begin{array}{c}\text { With the combination use of polyurethane } \\
\text { polymer and assistant rails }\end{array}$ \\
\hline $\begin{array}{l}\text { Maximum rail accelerations } \\
\begin{array}{l}\text { Reduction ratio compared with without } \\
\text { settlement (\%) }\end{array}\end{array}$ & 201.3 & 168.1 & 149.7 \\
\hline
\end{tabular}

polyurethane, and two less-abrupt stiffness change points occur at the borders. The maximum vehicle acceleration decreased further to $0.035 \mathrm{~g}$ after adding assistant rails with a maximum reduction of $45.3 \%$ relative to the abrupt track stiffness change (without settlement) as shown in Figure 9(c) and Table 3. In addition, the two newly introduced acceleration peaks were eliminated. Therefore, the measured results from the site clearly prove the combination of polyurethane and assistant rails effectively reduces the vehicle vibration at full line speeds, which improves the vehicle operational safety.

3.3.3. Vertical Acceleration Distribution of the Rail. The maximum vertical accelerations of the rail at each measurement point are recorded and shown in Figure 10. Moreover, the maximum rail accelerations and their reduction ratios for different track stiffness transition patterns are also calculated and shown in Table 4 . The maximum rail acceleration reached $201.3 \mathrm{~g}$ when there was no settlement in the transition zone. Therefore, the track geometry deterioration often occurs at the transition. Additionally, after applying polyurethane, the maximum rail acceleration decreased from $201.3 \mathrm{~g}$ to $168.1 \mathrm{~g}$ with a maximum reduction of $16.5 \%$. After adopting assistant rails, the maximum rail acceleration decreased further to $149.7 \mathrm{~g}$ with a maximum reduction of $25.6 \%$. This reductions result from the successive application of polyurethane polymer and assistant rails causing a more even change in vertical stiffness within the transition zone, which reduces the vertical wheel-rail force. Hence, combining polyurethane and assistant rails effectively improved the overall track safety and operation.

\section{Conclusions}

This paper improved the traffic performance, track safety, and passenger comfort during transitions between ballasted and ballastless track by applying polyurethane and assistant rails. Polyurethane alone and in combination with assistant rails was tested in-situ to evaluate the effect on the static and dynamic transition properties of a transition zone in the Chinese Liupanshui-Zhanyi railway with no settlement.

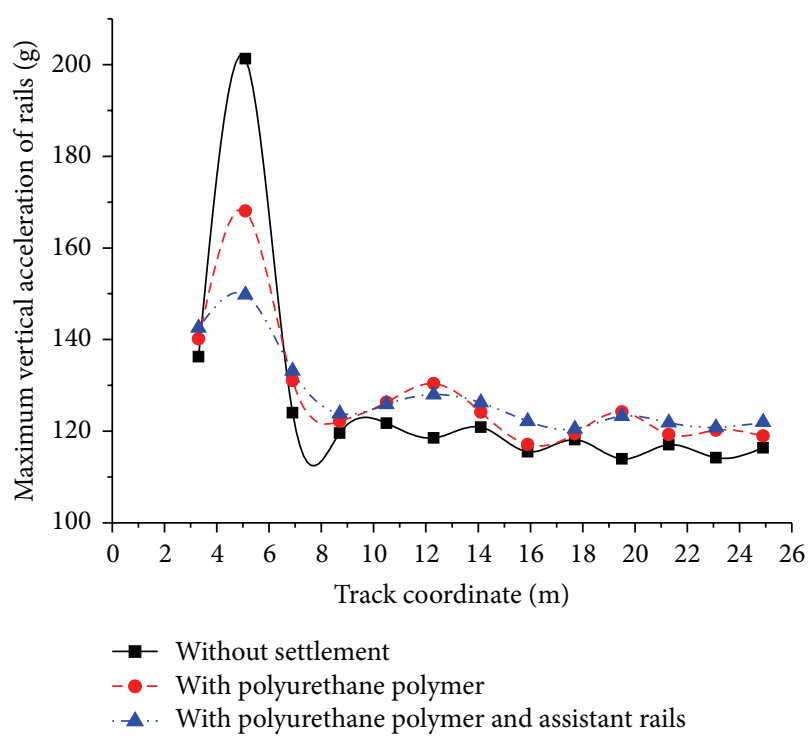

FIgURE 10: The maximum vertical accelerations of the rail at each measuring point.

Three conclusions were drawn by comparing the three transition types.

(1) The transition zone with no settlement exhibited a sudden vertical track stiffness change. After applying polyurethane, this sudden track change was more even. However, only after also installing the assistant rails did the vertical track stiffness exhibit its best change pattern. Thus, combining polyurethane and assistant rails was the most effective measure to control abrupt vertical track stiffness changes during the transition between ballasted and ballastless track.

(2) Applying polyurethane polymer could increase the track decay rates in the transition zone at frequencies above $100 \mathrm{~Hz}$. The track decay rates were further improved after installing the assistant rails. Therefore, constructing transition sections between ballasted and ballastless tracks in highspeed passenger-dedicated lines with both polyurethane and 
assistant rails is recommended to attenuate the track vibration.

(3) The sensible use of polyurethane in the transition zones significantly reduced the vertical wheel-rail interaction force and vehicle-track system dynamic response. Adding assistant rails further decreased the interaction force and dynamic response. The maximum reduction in the wheel-rail contact forces for the transition occurred with polyurethane alone and when adding the assistant rails and was $53.4 \%$ and $84.6 \%$ for the left wheel and $46.2 \%$ and $83.3 \%$ for right wheel, respectively, compared to having no settlement; the maximum vehicle acceleration reductions were $32.8 \%$ and $45.3 \%$, respectively; the vertical rail acceleration was reduced by $16.5 \%$ and $25.6 \%$, respectively. Hence, combining polyurethane with assistant rails effectively reduced vehicle vibrations at full line speeds, which improved the vehicle operating safety and overall track safety.

This paper proposes the use of polyurethane polymer alone and the combination use of polyurethane polymer and assistant rails as a measure for the settlement of abnormal strong vibrations produced in the vehicle-track system in the transition section between ballasted and ballastless track. The in-situ test results show that the combination use of polyurethane polymer and assistant rails is more reasonable and effective. However, the measurement introduced in this paper was taken on a condition that the two settlements were in a short-term operation. And the physical and mechanical properties of polyurethane polymer are related to atmospheric pressures, loading times, and environment temperatures [16]. Therefore, similar measurements on the test section mentioned in this paper with the settlement in a long-term operation will be taken for further research.

\section{Conflict of Interests}

The authors declare that there is no conflict of interests regarding the publication of this paper.

\section{Acknowledgments}

Thanks are owed to the NSFC (National Natural Science Foundation of China, no. U1234201) for the research grant awarded to the corresponding author. The work described in this paper was supported by the National Natural Science Foundation of China (51008018) and the Research Fund for the Doctoral Program of Higher Education of China (20090009120020).

\section{References}

[1] X. Lei and L. Mao, "Dynamic response analyses of vehicle and track coupled system on track transition of conventional high speed railway," Journal of Sound and Vibration, vol. 271, no. 3-4, pp. 1133-1146, 2004.

[2] P. Sharpe, R. J. Armitage, W. G. Heggie, and A. Rogers, "Innovative design of transition zones," in Proceedings of the International Conference on Railway Engineering, p. 12, London, UK, July 2002.
[3] Y. Shan, B. Albers, and S. A. Savidis, "Influence of different transition zones on the dynamic response of track-subgrade systems," Computers and Geotechnics, vol. 48, pp. 21-28, 2013.

[4] J. N. Varandas, P. Hölscher, and M. A. G. Silva, "Dynamic behaviour of railway tracks on transitions zones," Computers \& Structures, vol. 89, no. 13-14, pp. 1468-1479, 2011.

[5] D. Li, D. Otter, and G. Carr, "Railway bridge approaches under heavy axle load traffic: problems, causes, and remedies," Proceedings of the Institution of Mechanical Engineers. Part F: Journal of Rail and Rapid Transit, vol. 224, no. 5, pp. 383-390, 2010.

[6] B. Coelho, P. Hölscher, J. Priest et al., "An assessment of transition zone performance," Proceedings of the Institution of Mechanical Engineers F: Journal of Rail and Rapid Transit, vol. 225, no. 2, pp. 129-139, 2011.

[7] T. Dahlberg, "Railway track stiffness variations-consequences and countermeasures," International Journal of Civil Engineering, vol. 8, no. 1, pp. 1-12, 2010.

[8] M. J. M. M. Steenbergen, "Physics of railroad degradation: the role of a varying dynamic stiffness and transition radiation processes," Computers \& Structures, vol. 124, pp. 102-111, 2013.

[9] X. Lei and B. Zhang, "Influence of track stiffness distribution on vehicle and track interactions in track transition," Proceedings of the Institution of Mechanical Engineers. Part F: Journal of Rail and Rapid Transit, vol. 224, no. 6, pp. 592-604, 2010.

[10] B. Coelho, P. Hölscher, J. Priest, W. Powrie, and F. Barends, "An assessment of transition zone performance," Proceedings of the IMechE Part F: Journal of Rail and Rapid Transit, vol. 225, no. 2, pp. 129-139, 2011.

[11] J. Shi, M. P. N. Burrow, A. H. Chan, and Y. J. Wang, "Measurements and simulation of the dynamic responses of a bridgeembankment transition zone below a heavy haul railway line," Proceedings of the Institution of Mechanical Engineers, Part F: Journal of Rail and Rapid Transit, vol. 227, no. 3, pp. 254-268, 2013.

[12] C. Chen and G. R. McDowell, "An investigation of the dynamic behaviour of track transition zones using discrete element modelling," Proceedings of the Institution of Mechanical Engineers Part F: Journal of Rail and Rapid Transit, Article ID 0954409714528892, pp. 1-12, 2014.

[13] J. N. Varandas, P. Hölscher, and M. A. G. Silva, "Settlement of ballasted track under traffic loading: application to transition zones," Proceedings of the Institution of Mechanical Engineers Part F: Journal of Rail and Rapid Transit, vol. 228, no. 3, pp. 242259, 2014

[14] C. J. C. Jones, D. J. Thompson, and R. J. Diehl, "The use of decay rates to analyse the performance of railway track in rolling noise generation," Journal of Sound and Vibration, vol. 293, no. 3-5, pp. 485-495, 2006.

[15] J. Ryue, D. J. Thompson, P. R. White, and D. R. Thompson, "Decay rates of propagating waves in railway tracks at high frequencies," Journal of Sound and Vibration, vol. 320, no. 4-5, pp. 955-976, 2009.

[16] R. J. Young and P. A. Lovell, Introduction to Polymers, CRC Press, Boca Raton, Fla, USA, 3rd edition, 2011. 

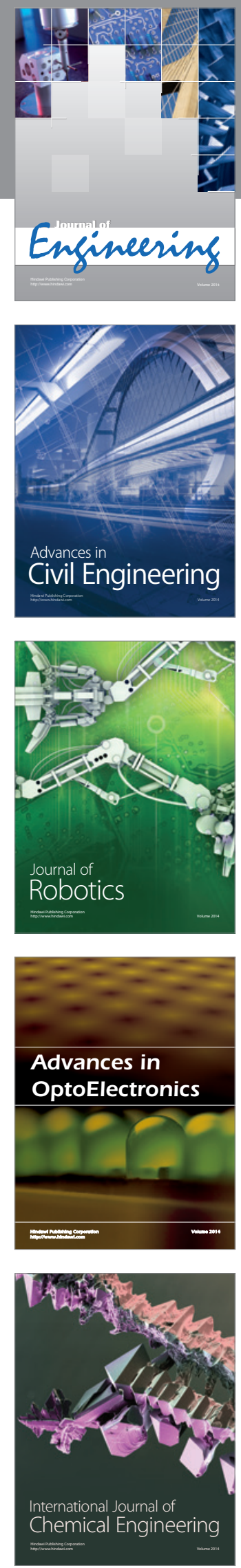

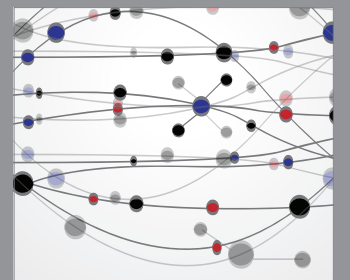

The Scientific World Journal
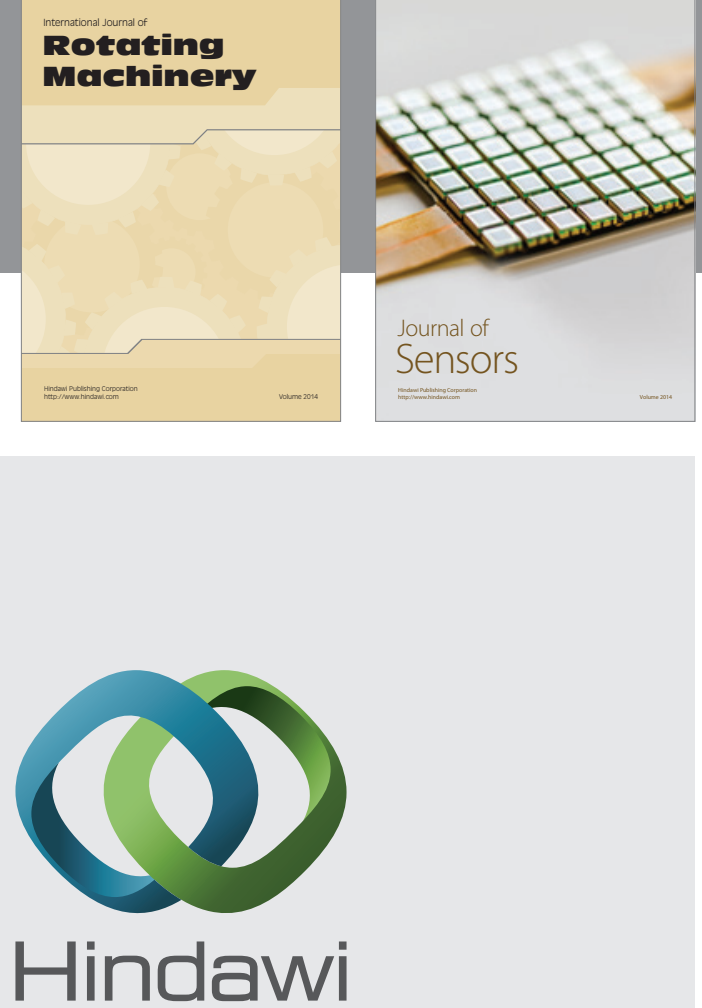

Submit your manuscripts at http://www.hindawi.com
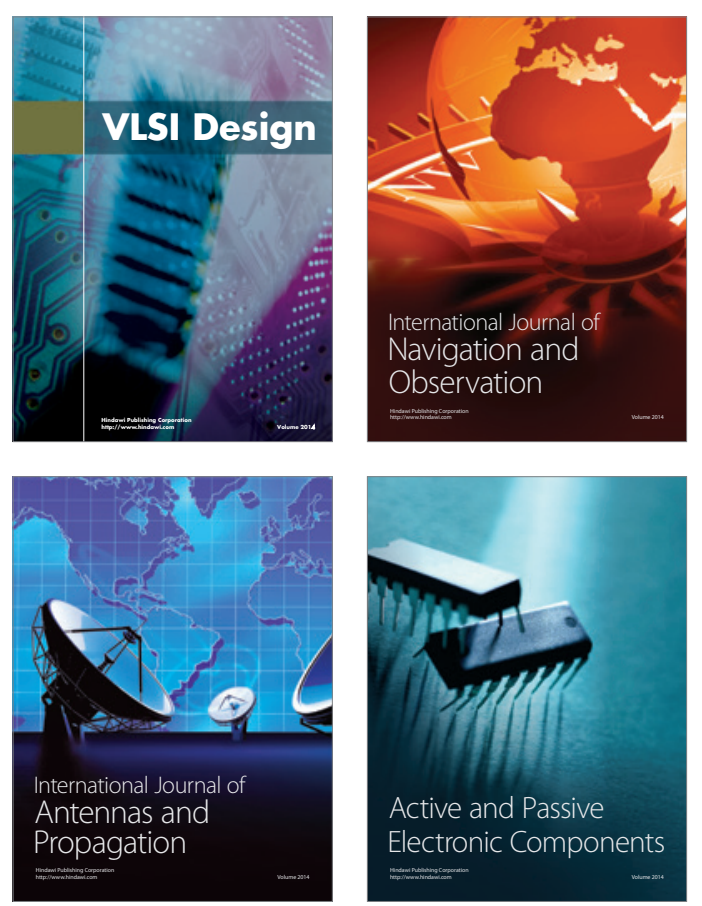
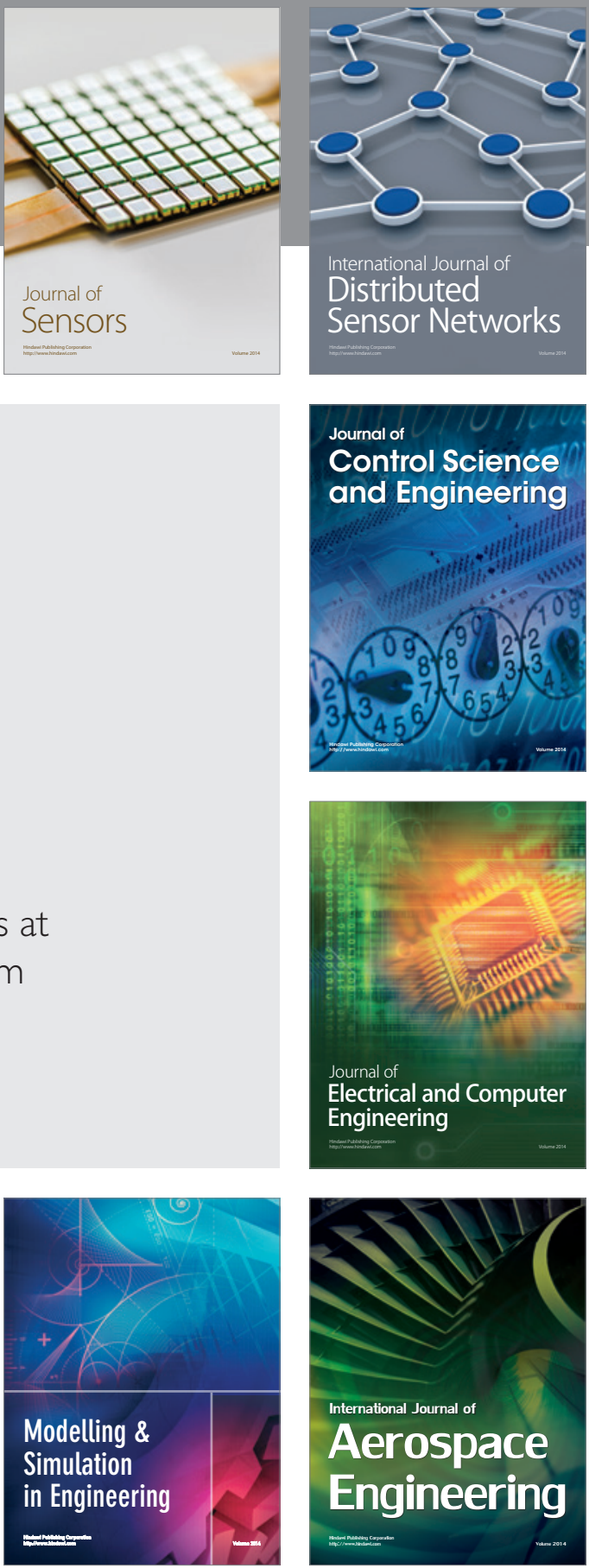

Journal of

Control Science

and Engineering
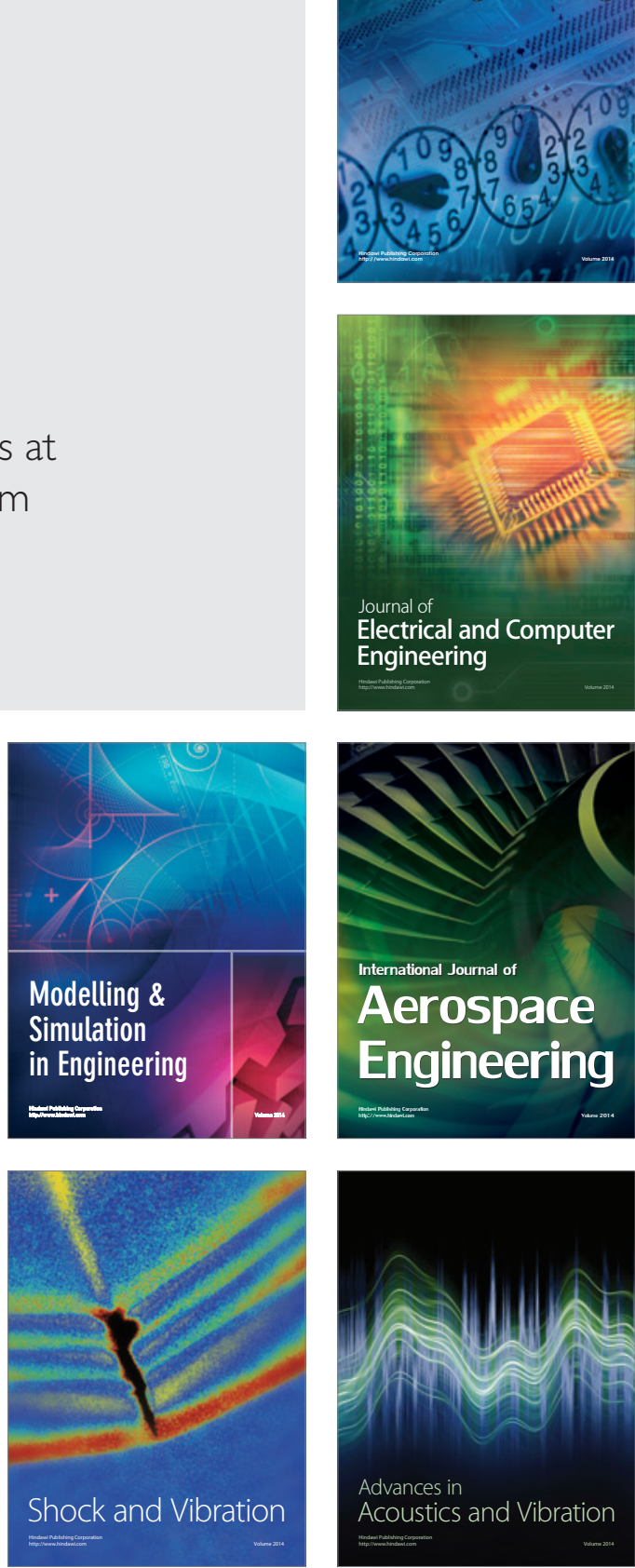